\title{
Survival of heart failure patients with reduced and preserved ejection fraction is not different!
}

\author{
(1)Azra Durak- \\ Nalbantić*, \\ (1)Alen Džubur, \\ - Nafija Serdarević, \\ (D)Aida Hamzić- \\ Mehmedbašić, \\ (D)Faris Zvizdić, \\ DEnisa Hodžić, \\ - Marina Vučijak- \\ Grgurević, \\ (D)Alden Begić, \\ DAkif Mlaćo, \\ Denisa Gljiva-Gogić
}

Clinical Center of the University of Sarajevo, Sarajevo, Bosnia and Herzegovina

\begin{abstract}
KEYWORDS: heart failure, mortality.
CITATION: Cardiol Croat. 2019;14(9-10):221. | https://doi.org/10.15836/ccar2019.221

*ADDRESS FOR CORRESPONDENCE: Azra Durak-Nalbantić, Bolnička 25, 71000 Sarajevo, Bosnia and Herzegovina. / Phone: +38761221199 / Email: azradurak@yahoo.com

ORCID: Azra Durak-Nalbantić, https://orcid.org/0000-0002-5175-8941 • Alen Džubur, https://orcid.org/0000-0003-1198-540X Nafija Serdarević, https://orcid.org/0000-0001-7977-9819 • Aida Hamzić-Mehmedbašić, https://orcid.org/0000-0002-4967-7616 Faris Zvizdić, https://orcid.org/0000-0001-7647-2723• Enisa Hodžić, https://www.orcid.org/0000-0002-7436-7708 Marina Vučijak-Grgurević, https://orcid.org/0000-0002-3755-0968 • Alden Begić, https://orcid.org/0000-0002-5374-0892 Akif Mlaćo, https://orcid. org/0000-0002-1907-9017• Zenisa Gljiva-Gogić, https://orcid.org/0000-0002-9369-5571
\end{abstract}

IIIIIIIIIIIIIIIIIIIIIIIIIIIIIIIIIIIIIIIIIIIIIIIIIIIIIIIIIIIIIIIIIIIIIIIIIIIIIIIIIIIIIIIIIIIIIIIIIIIIIIIIIIIIIIIIIIIIIIIIII

Introduction: A progress in the management of cardiovascular disease leads to a decrease in mortality, but heart failure (HF) seems to be an exception. Today, the rate of rehospitalization and mortality after acute heart failure is still very high. Lower ejection fraction (EF) means worse prognosis, but recent studies are reporting that HF patients with preserved EF have no better survival compared to patients with reduced $\mathrm{EF}^{1}$. Goal: to investigate a possible difference in the outcome of HF patients with reduced (HFREF) and preserved ejection fraction (HFPEF).

Patients and Methods: In 222 patients hospitalized in acute HF (138 with reduced EF and 74 with preserved EF) were determined routine laboratory test, including BNP. The LVEF cutoff for diagnosing of HFPEF was above $45 \%$. Patients were followed for the next 18 months for the occurrence of 1. readmission due to repeat decompensation and 2. mortality.

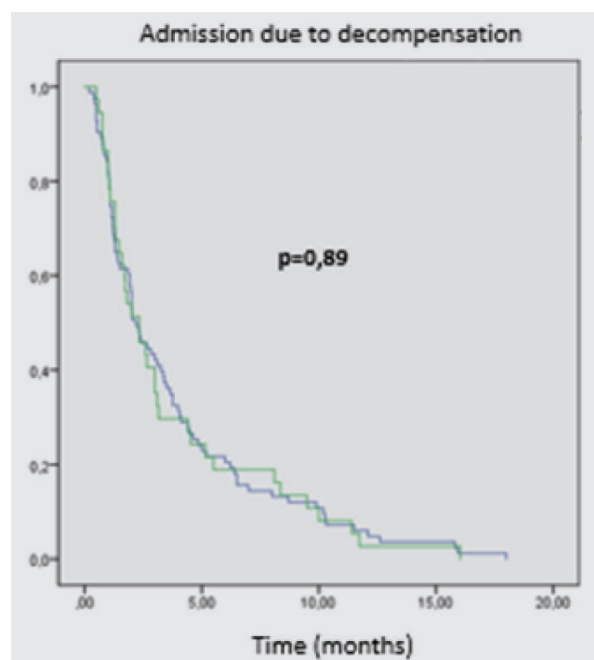

FIGURE 1. Admission due to decompensated heart failure in the group of heart failure patients with reduced (HFREF) and preserved ejection fraction (HFPEF).

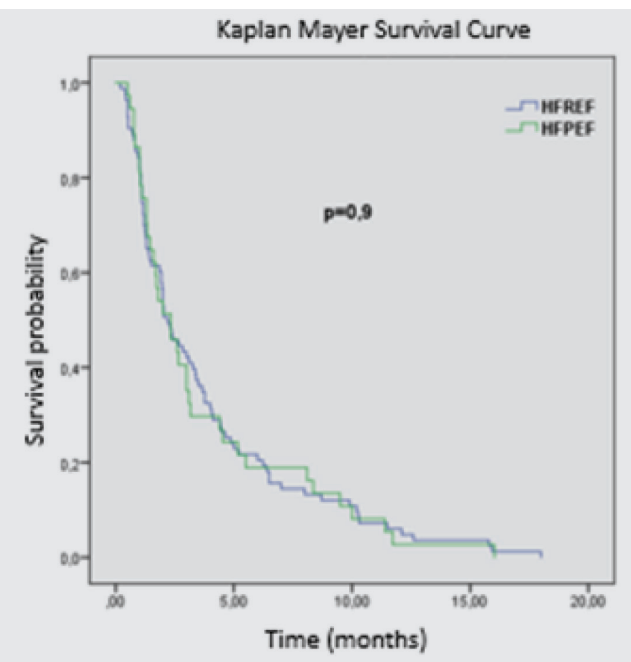

FIGURE 2. Kaplan-Meier survival curve in in the group of heart failure patients with reduced (HFREF) and preserved ejection fraction (HFPEF) in an 18-month period.

Results: BNP at discharge was higher in HFREF compared to HFPEF group [699.3 (271.8-1519.1) $\mathrm{pg} / \mathrm{ml}$ vs 263.3 (134.4-502.2) pg/ $\mathrm{ml}, \mathrm{p}<0.001]$. During 18-month follow-up 129 patients (58.11\%) were readmitted due to decompensation, but there was no significant difference between group: in HFREF group was hospitalized $87(63.04 \%)$ patients compared to $42(50 \%)$ patients in HFPEF group ( $p=0.077)$. There was no difference in the rate of readmission in 1-month $(\mathrm{p}=0.7)$ 6 -month $(p=0.24)$, and 12-month follow up $(p=0.16)$ in HFREF vs HFPEF group. In Kaplan-Meier curve there was no significant difference in the mean time of the occurrence of readmission due to decompensation: in HFREF group 2.2 (95\% CI=1.582.8) months and in HFPEF group

RECEIVED:

July 10, 2019

ACCEPTED:

September 16, 2019

2.33 (95\% CI=1.3-3.4) months ( $\mathrm{p}=0.89)$ (Figure 1). In HFREF 18-month survival was 43.5\% (60/138) and in HFPEF group was $56.0 \%(47 / 84)$ and the difference was not significant $(p=0,096)$. In the Kaplan-Meier curve, there was no difference in time of survival in 18-month follow-up ( $\mathrm{p}=0.9)$ : mean time of survival in HFREF was 3.8 (95\% CI=3.0-4.7) months and in HFPEF 3.75 (95\% CI=2.5-5.0) months (Figure 2). There was no difference in mortality in 1-month ( $p=0.8), 6$-month ( $p=0.16)$ and 12-month follow up $(p=0.08)$.

Conclusion: Rate of rehospitalization due to decompensation and mortality is not different between HFREF and HFPEF group. Preserved EF is not related to better survival in patients with HF.

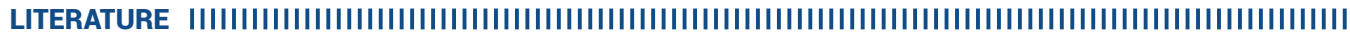

1. Shah KS, Xu H, Matsouaka RA, Bhatt DL, Heidenreich PA, Hernandez AF, et al. Heart Failure With Preserved, Borderline, and Reduced Ejection Fraction: 5-Year Outcomes. J Am Coll Cardiol. 2017 Nov 14;70(20):2476-2486. https://doi.org/10.1016/j.jacc.2017.08.074 